ISSN No. 0974-035X

An Indexed, Refereed \& Peer Reviewed Journal of Higher Education

Towards Excellence

UGC-HUMAN RESOURCE DEVELOPMENT CENTRE,

GUJARAT UNIVERSITY, AHMEDABAD, INDIA

\title{
INTEGRATING SKILL DEVELOPMENT IN HIGHER EDUCATION: A COMPARATIVE ANALYSIS OF INDIA AND CANADA
}

\section{Dr. Mayur Wadhwaniya}

\begin{abstract}
The paper presents a comparative analysis of two emerging economies -India and Canada in case of Skill development in Higher education. The rational for comparing India and Canada is because both countries have a common underline philosophy when it comes to skill development in Higher education. In both the countries, Skill development in Higher Education' has been central for policy makers, academicians and international education community merely because of the fact that a skilled workforce with quality higher education has the potential to be productive and can contribute immensely to the economic growth and development of the country. Universities and Institutes of higher learning across the globe are in constant pressure to ensure that their graduates are 'employable' but it is found that most of the university courses are rarely able to provide a 'decent employment' just because of the fact that the curriculums in the university system does not have the component of skill development. This backdrop raises a very fundamental question; what is the extent of importance given to skill development especially in Higher education and how it can be improved further?
\end{abstract}

The analysis so far shows that the Government of Canada has considered skill development as a essential part of higher education over years. However, there are criticism like Canada's skills and education performance is deteriorating, that not enough is being done to address a range of economic and social problems, and that opportunities and benefits have been poorly distributed across regions and groups.

In India, education and skill development sector is structured under two independent ministries. The Ministry of Human Resource and Development is associated with conventional education system. There are many initiatives for skill development by the Government like National Skill Development Coordination Board, NSDC is setup on a PPP 
model. It is a juxtaposition of public sector and private entities. The board formulates policies and programs on National Skill Development under the ambit of Prime Minister's Council. It also evaluates and monitors the outcomes of such programs. But still unlike Canada the efforts subject criticism. Therefore still there is a need to put greater impetus on skill development and vocational institutes to push growth of the economy should be facilitated through suitable policy framework and ensure awareness among the employers to take certified skilled workers and fixing the lower limit of pay-scale.

Key Words: Higher Education, Skill Development, Employment

\section{Introduction:}

Globalization, knowledge and competition have intensified the need for highly skilled workforce in both the developing and developed nations as it enables them to accelerate the growth rate of their economy towards higher trajectory. Today all economies need skilled workforce so as to meet global standards of quality, to increase their foreign trade, to bring advanced technologies to their domestic industries and to boost their industrial and economic development. Thus, skills and knowledge becomes the major driving force of socio-economic growth and development for any country. As it has been observed that countries with highly skilled human capital tend to have higher GDP and per capita income levels and they adjust more effectively to the challenges and opportunities of the world of work. (Saini, 2015)

\subsection{The Indian Scenario:}

The global economy is undergoing structural transformation: there will be need for a workforce of 3.3 billion by 2020, increasingly in the services and capital intensivemanufacturing sectors. The phenomena is also expected to play out in India - by $2020,90 \%$ of India's GDP and 75\% of employment is expected to be contributed by the services and manufacturing sectors. Technological advancement will make several jobs redundant while also creating new job roles. This structural shift in employment will increase demand for sophisticated workers, innovators, and thinkers who can thrive in a globally-connected and dynamic economy. India, with its large workforce and increasing pool of higher education graduates, is strategically positioned to reap the benefits of this shift. However, the 'demographic divided' will be squandered unless India is able to create a "globally relevant and competitive" higher education system that serves the requirements of both the domestic as well as global economy. (EY \& FICCI, 2014) 


\section{Dr. Mayur Wadhwaniya / Page 93-106}

Government plans are in place to transform the sector over the next five years. Every aspect of higher education is being reorganised and remodelled: funding, leadership and management, quality assurance, accountability, relationships with industry, international collaboration, and the way research and teaching are conducted. If these reforms succeed, the breadth and depth of the change will be transformational. The Indian government is planning huge expansion at all levels of education. While there is no doubt that this will be the decade of change at a transformational scale and pace, India's rise faces daunting challenges. The education system as a whole is beset with issues of quality, access and equity, and change is happening much faster in some states than others. The general standard of education in India is low. There are not enough places in schools, colleges or universities to cope with the enormous and increasing demand. Traditional approaches to meet this demand will not be sufficient in the time-scale needed. With the rise of the middle classes, an increasing number of people need not rely on the state to provide an education service. As a consequence, India has seen a dramatic shift towards private provision across the entire education spectrum, including higher education. The private sector is already playing a significant role in the development of education in India, and its influence and presence will increase substantially. Education is vital for India's competiveness and economic growth, but also for social stability. The disparity between rich and poor is growing, and expectations on the part of young people and their parents are high. Geographical differences are vast, compounded by social divisions and inequalities in education provision (British Council, 2014)

Over the last decade, higher education has been on a steep growth trajectory. India now has the largest higher education system in the world in terms of the number of institutions, and the second largest in terms of the number of students. However, despite impressive growth, India's higher education gross enrolment ratio (GER) at $18 \%$ is currently well below the global average of $27 \%$. This difference is even more stark when compared to China and Brazil at $26 \%$ and $36 \%$ respectively. The government plans to increase GER in higher education to $30 \%$ by 2020 . This will require a transformational change at a pace and scale never seen before. As India currently has 26 million students enrolled in tertiary education, by illustration, it would need another 800 universities and over 40,000 colleges in the next eight years to provide the planned additional 14 million places ( 40 million places by 2020). At current growth rates, India will fall very far short of this figure, therefore the Indian government has put an ambitious five-year plan into place to boost the rate of expansion significantly. (British Council, 2014) 


\section{Present Scenario of Skill Capacity of India:}

In order to capitalize the demographic dividend, India will need to empower its workers with the right type of skills. Thus this section depicts the present skill levels of the Indian workforce in the age group of 15-59 years in the form of their general educational levels and vocational training levels.

- The drop-out rates of educational institution was estimated to be 50\% in the age group of 514 years and $86 \%$ after 15 years of age and in contrast to this the participation rate of the workforce rises rapidly after 14 years of age and it results in a semi-literate workforce which finds it difficult to absorb higher form of skills.

- $38 \%$ of Indian workforce is illiterate, $25 \%$ has education below primary or up to primary level and remaining 36\% has an education level of middle and higher level.

- $80 \%$ of Indian workforce does not possess any marketable skills.

- Only about $2 \%$ have received formal vocational training and $8 \%$ non-formal vocational training, thereby implying that very few new entrants to the work force have any marketable skills as compared to developed economies such as Korea (96\%), Germany (75\%), Japan (80\%) and United Kingdom (68\%).

In-nutshell, it can be said that despite making considerable progress in terms of literacy, high incidence of illiteracy cripples the Indian workforce even today. The above facts are a stark reminder that India's demographic dividend can rapidly convert into a demographic nightmare if skills are not provided to both new and existing workforce.

Thus, there is a need for increasing capacity and capability of skill development programs. In this direction, both the Government and its partner agencies have undertaken various measures/ initiatives for the effective implementation of the skill development system in the economy. But still India faces a number of unresolved issues and challenges that need immediate attention of the policy makers. Hence, the next section deals with some of these bottlenecks along with their way outs. (Saini, 2015)

\section{Model for Higher Education and Skill Development in India:}




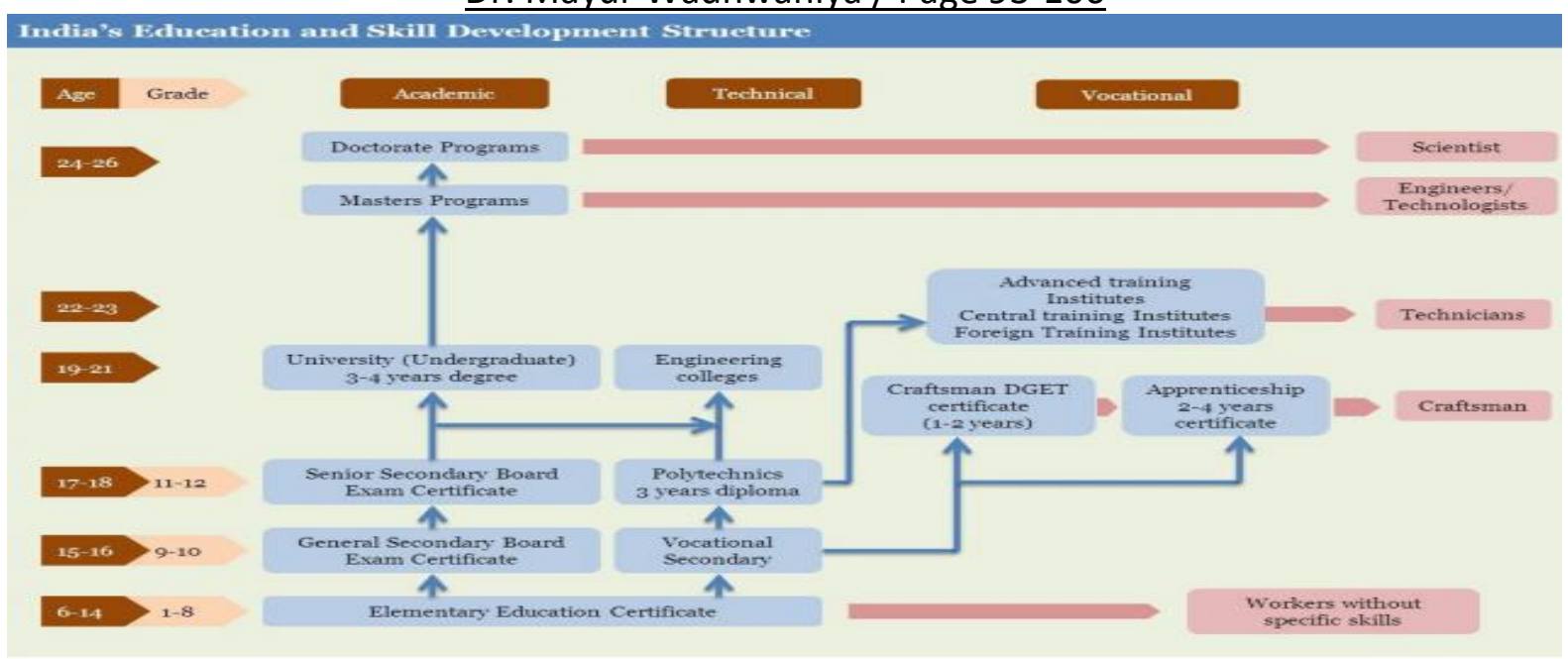

Source : World Bank

The skill development ecosystem in India is complex, large and diverse, providing varied levels of skills across an extremely heterogeneous population. Skill development in India can be broadly segmented into Education and Vocational Training. The exhibit below presents the broad framework of Skill Development in India. Elementary, secondary and higher education is governed by the Ministry of Human Resource Development. University and Higher Education caters to all college education (Arts, Science, Commerce, etc.), while engineering education, polytechnics, etc. fall under Technical Education. University Grants Commission (UGC) is the nodal body governing funds, grants and setting standards for teaching, examination and research in Universities, and the All India Council for Technical Education (AICTE) is the regulatory body for Technical Education in India. Skills in India are acquired through both formal and informal channels. Formal vocational training is imparted in both public and private sector. Some of the major channels of formal vocation training include the government-run Industrial Training Institutes (ITIs), privately operated Industrial Training Centres (ITCs), vocational schools, specialized institutes for technical training, and apprenticeship training by the industry.

The private sector participation has been on a rise lately, but the sector continues to be dominated by the public sector. Informal training on the other hand refers to experiential skills acquired on the job. At the central level, the nodal institution for vocational training is the Director General of Employment \& Training (DGET) under the Ministry of Labour and Employment. The DGET is responsible for formulating policies, establishing standards, granting affiliation, trade testing and certification, and matters connected to vocational training and providing employment services. The National Skill Development Council (NSDC) - now a part of the newly created Ministry of Skill Development and 
Entrepreneurship - was initially set up under the Ministry of Finance to provide viability gap funding and promote private skill initiatives.

\section{Possible Frameworks so far:}

The Indian Government has listed skill development as one of its priorities and aims to enhance participation of youth, seek greater inclusion of women, disabled and other disadvantaged sections into the workforce, and improve the capability of the present system, making it flexible to adapt to technological changes and demands emanating from the labour market. Currently, skill development efforts in India are spread across approximately 20 separate ministries, 35 State Governments and Union Territories and the private sector. A Ministry of Skills Development, Entrepreneurship, Youth and Sports was created when the Modi government took charge in mid-2014. The Ministry has been entrusted with the coordination of all stakeholders during the evolution of an appropriate skills development framework, removal of disconnect between demand and supply of skilled manpower, skills up gradation, building new skills, innovative thinking and assuring availability of talent. (EY \& FICCI, 2014)

\subsection{The Apprenticeship Act of 1961}

Apprenticeship programmes in India are governed by The Apprentice Act of 1961 and the Apprenticeship Rules of 1992. The organizational structure and rules and regulations overseeing it are complex and burdensome. The Apprentice Training Scheme is implemented by the ministries of Labour and Employment and Human Resource Development. The Ministry of Labour and Employment oversees 'trade apprentices' through six regional offices. The Ministry of Human Resource Development oversees 'graduate, technician, and technician (vocational) apprentices' through four boards located in different cities. The Act regulates programmes of training of apprentices and makes it obligatory for employers in both public and private sector establishments to have training infrastructure as detailed in the Act. This has been primarily to ensure trainees get optimum access to real work environment and on-the-job training. One of the objectives of apprenticeship was also to ensure that employers get skilled workforce having adequate exposure to real work environment. About 254 groups of industries are covered under the Act and about 27,000 establishments engage apprentices(EY \& FICCI, 2014)

\subsection{The National Skill Policy}

The National Policy on Skill Development was first formulated in 2009 to create a skills ecosystem in India. It acts as a guide to formulate strategies by addressing the different 
challenges in skill development. The objective is to empower the workforce with the required skills, knowledge and qualifications to make the Indian workforce globally competitive. The government has introduced a National Policy on Skill Development and Entrepreneurship, 2015. The policy aims to provide an umbrella framework to all skill related activities carried out within the country, to align them to common standards and link skill activities with demand centres. In addition to laying down the objectives and expected outcomes, it aims at identifying various institutional frameworks which can act as the vehicle to reach the expected outcomes. The new skills policy also provides details on how skill development efforts across the country can be aligned within the existing institutional arrangements. (EY \& FICCI, 2014)

\subsection{The National Skills Qualification Framework}

The National Skills Qualifications Framework (NSQF), notified on 27th December 2013, is a competency-based framework that organizes all qualifications according to a series of levels of knowledge, skills and aptitude. Presently, more than 100 countries have, or are in the process of developing national qualification frameworks. Under NSQF, the learner can acquire the certification for competency needed at any level through formal, non-formal or informal learning. The NSQF is anchored at the National Skill Development Agency (NSDA) and is being implemented through the National Skills Qualifications Committee (NSQC) which comprises of all key stakeholders. (EY \& FICCI, 2014)

\section{Skill Development Eco-System in India:}

Key Bodies
- Ministry of Skill
Development \&
Entrepreneurship
- MHRD
- Ministry of Rural
Development
(MoRD)
-Other Central
Ministries

Enablers

- State Skill
Development
Mission (SSDM)
- NSDC
- NSDA
- SSCs
- NCVT
- SCVT
- Labour Laws
- Minimum Wages Act
- Financial
Institutions
- Apprenticeships Act

Implementing
Bodies
- ITIs
- Training Providers
- Captive Training by
Employers
- Schools
- Universities
- Assessment
Companies

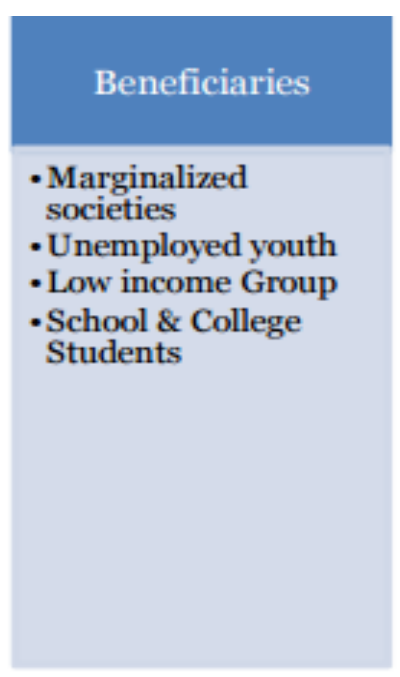

Ministry of Human Resource and Development (MHRD) 
The Ministry of Human Resource and Development (MHRD) governs the polytechnic institutions offering diploma level courses under various disciplines such as engineering and technology, pharmacy, architecture, applied arts and crafts and hotel management. MHRD is also involved in the scheme of Apprenticeship Training MHRD. The Ministry of Human Resource and Development (MHRD) governs the polytechnic institutions offering diploma level courses under various disciplines such as engineering and technology, pharmacy, architecture, applied arts and crafts and hotel management. MHRD is also involved in the scheme of Apprenticeship Training (EY \& FICCI, 2014)

\subsection{Enabling agencies}

- NSDC: The National Skill Development Corporation India (NSDC) is a public private partnership organisation (now under the Ministry of Skill Development and Entrepreneurship) that was incorporated in 2009 under the National Skill Policy. Its main aim is to provide viability gap funding to private sector in order to scale up training capacity. The NSDC has tied up with more than 187 training providers, many of whom have started scaling up their operations. (EY \& FICCI, 2014)

- Sector Skill Councils : The National Skill Development Policy of 2009 mandated the NSDC to setup SSCs to bring together key stakeholders i.e. industry, work force and academia. As on date, 29 SSCs are operational and 4 more SSCs have been approved by NSDC . They are funded by NSDC for the initial few years and are expected to become financially self-sustaining as they grow(EY \& FICCI, 2014)

- NCVT, SCVT and Quality Council of India Established under Ministry of Labour and Employment with a view to ensure and maintain uniformity in the standards of training all over the country, the National Council for Vocational Training (NCVT) was set up in 1956. This certifying body conducts All India Trade Tests for those who complete training in ITIs and awards National Trade Certificates to successful candidates. The Council has representation from central and state government departments, employers' and workers' organisations, professional and learned bodies, All India Council for Technical Education, scheduled castes and scheduled tribes, All India Women's Organisation, among others. The State Council for Vocational Training (SCVT) at the state levels and the sub committees have been established to assist the National Council. (EY \& FICCI, 2014)

\section{Skill Development Challenges:}

\section{- Inadequate scale, limited capacity:}


The existing infrastructure, both physical and human, is grossly inadequate considering the projected demand for skilled labour. While there is a need to create additional capacity in existing institutes, at the same time there is a need to create an adequate infrastructure even in small towns and villages. In terms of faculty, too, the training infrastructure is inadequate. For instance, corresponding to the current seating capacity of about 1.7 million trainees at ITIs, there is a need of almost 85,000 trainers (considering 20:1 student/faculty ratio). As against this, the seating capacity for various trainers' programme of DGET is just 4,438, which is far from adequate to meet the requirement. (EY \& FICCI, 2014)

- Awareness, mind-set and perception issues :

Skill development in India is way below the requirements due to a lack of awareness on the type of courses as well as information on the ensuing career prospects. More importantly, there is limited acceptance of skill development courses as a viable alternative to formal education. Skilling is often viewed as the last resort meant for those who have not been able to progress in the formal academic system. This is partly to do with the lack of integration between the two options and also due to rising aspirations for white collar jobs which necessitate higher qualifications. Moreover, skill development is often associated with blue collar jobs, which is largely perceived to be of low dignity and provides low wages/salaries. (EY \& FICCI, 2014)

\section{- Cost concerns}

Skill development initiatives in India continue to be largely dependent upon the government funds or public-private ventures. Owing to high capital requirements and low return on investments, skill development is often looked at as a non-scalable model and remains underinvested. Additionally, a fee-based model also faces challenges as prospective students are often unwilling or unable to pay high fees for training. Even the bank's willingness to lend for skill development activities is low as educational loans are perceived as high risk products due to uncertainty with respect to future employment. (EY \& FICCI, 2014)

\section{- Quality concerns}

There is a serious mismatch between the industry's requirements and the skills imparted in educational and training institutes, especially for the mid-level skills requiring some expertise on handling of machinery. To tackle this problem, considerable improvement of the quality of training is needed. The issue relates to the quality of infrastructure, trainers, as well as curricula and pedagogy. In terms of infrastructure, the institutes often lack appropriate machinery to give students hands- 
on training. Even the course curricula often are outdated, redundant and non standardised. Additionally, the lack of industry-faculty interaction on course curricula leads to irrelevant training modules(EY \& FICCI, 2014)

\section{- Mobility concerns}

In India, educational qualification is generally preferred over vocational training as former is associated with better employment opportunities, in terms of pay as well as quality of work. Additionally, there is limited mobility between formal education and vocational training in India due to lack of equivalent recognition for the latter; a student enrolled in vocational training often cannot migrate to institutes of higher education due to eligibility restrictions (EY \& FICCI, 2014)

\section{The Canadian Scenario:}

Canada's performance in higher education and skills development has been fairly strong for many years. On key measures we are at or near the top of international rankings and our highly skilled people contribute to economic competitiveness, social innovation, and political and community well-being. But there are troubling indications that Canada's skills and education performance is deteriorating, that not enough is being done to address a range of economic and social problems, and that opportunities and benefits have been poorly distributed across regions and groups. In short, there are signs that we are not doing enough to achieve the high levels of skills excellence and equity we need.

Action is needed to sustain and enhance the performance of higher education and skills development in Canada. Higher education and the development of advanced skills are not for all Canadians. Some may simply choose to pursue other paths. But in too many cases, participation and achievement are determined not by choice, but by circumstances over which individuals have little control. Where communities and governments have power to shape those circumstances it is imperative that we discuss whether and how to do so. In addition to designing and pursue an excellence agenda for skills and higher education, we need to design and pursue an equity agenda. (Munro, 2014)

\section{Potential Challenges:}

\subsection{Aboriginal Achievement:}

Many who identify as Aboriginal have earned university, college and/or trades credentials and many exhibit advanced skills that contribute to economic, social, and individual wellbeing. But there is a large achievement gap between Aboriginal and non- Aboriginal 
individuals that contrasts sharply both with Canada's egalitarian values and responsibilities to Aboriginal peoples. (Munro, 2014)

\subsection{Gaps in Skills Development:}

There are also substantial gaps between Aboriginals and non- Aboriginals in the development of core skills. PIAAC results show that, on average, the Aboriginal population scores below the non-Aboriginal population in both literacy and numeracy. On average, the Aboriginal population scored 260 (out of 500) in literacy versus 274 for the non-Aboriginal population. The average numeracy score for the Aboriginal population was 244 versus 266 for the nonAboriginal population. The size of the gaps varies across provinces and territories, and it narrows or widens in different age cohorts. But across all provinces, territories and age groups tested, the Aboriginal population consistently scores below the non-Aboriginal population. (Munro, 2014)

\subsection{Skills Development by Educational Attainment:}

However, comparing the skills attainment of Aboriginal and non-Aboriginal populations with similar levels of education reveals an interesting picture. Similarly educated cohorts of Aboriginal and non-Aboriginal individuals achieve nearly identical literacy scores and similar numeracy scores .Among those with Bachelor's degrees or higher, Aboriginal graduates score slightly higher on literacy (305) than non- Aboriginal graduates (300) (Munro, 2014)

\subsection{Labour Market Outcomes:}

Higher education and skills attainment for Aboriginals is not always associated with better labour market outcomes. Aboriginals with PSE credentials have lower employment and participation rates, and higher unemployment rates, than non-Aboriginals with PSE credentials. And although Aboriginal graduates earn higher incomes than Aboriginal nongraduates, there is persistent income inequality between Aboriginal and non-Aboriginal graduates(Munro, 2014)

\subsection{Gender Gaps:}

Differences in skills and higher education achievement between Canadian men and women are another challenge. On some measures, men outperform women, while in others the reverse is true. Notable differences in the kinds of higher education paths men and women pursue and the benefits they experience are another issue to examine. (Munro, 2014) 


\subsection{Regional Differences:}

There are substantial differences between provinces and territories in higher education attainment and skills development. Many factors help to explain the differences-including demographics, funding, institutional structures, regional labour markets and others - but there are complex interactions among these factors and focusing on only one or even a few is unlikely to repair the gaps. Recognizing that more investigation will be required, a good start is simply to understand where we are in terms of higher educational attainment and skills development (Munro, 2014)

\section{Policy Options adopted by Canada:}

On average, Canada performs well in terms of higher education attainment and on some skills measures. But there are ongoing and emerging challenges with respect to graduates' skills (both quality and kinds), insufficient advanced and STEM degree attainment, and inadequate opportunities for workplace training. As the economy becomes more technology- and knowledge-intensive, and our ability to address emerging and persistent policy challenges requires ever-increasing levels of scientific and cultural literacy, it is imperative that governments and PSE institutions in Canada adopt an excellence agenda for skills and higher education. (Munro, 2014)

\subsection{Create a National Learning Outcomes Assessment Program}

To track and improve the skills development performance of higher education institutions, the federal and provincial governments should work together to establish a national learning outcomes assessment program. (Munro, 2014)

\subsection{Create a Canadian Council on Skills and Higher Education}

To ensure that Canadian PSE institutions, employers, policymakers and other stakeholders have access to independent expertise, research and advice on skills and higher education, the federal government should establish an independent, arms-length Canadian Council on Skills and Higher Education (CCSHE). (Munro, 2014)

\subsection{Make significant new investments in education and skills for Aboriginal peoples}

To ensure that current and future generations of Aboriginal peoples in Canada achieve equitable skills and higher education opportunities and outcomes, the federal government should make substantial investments in foundational skills programs for Aboriginal youth and 
address barriers faced by Aboriginal peoples to higher education participation and completion (Munro, 2014)

\subsection{Improve credential recognition and skills training for immigrants.}

To improve the labour market participation and outcomes of immigrants, governments, institutions, and industry associations should work to improve credential recognition practices, and federal and provincial governments should invest more in skills development for recent immigrants. (Munro, 2014)

\subsection{Increase employer investments in skills training.}

To complement the skills development that occurs in higher education, and to ensure that they have the highly trained people they need, employers should increase investments in skills training. (Munro, 2014)

\section{Conclusion :}

To make India internationally competitive and to boost its economic growth further, a skilled workforce is essential. As more and more India moves towards the Knowledge economy, it becomes increasingly important for it to focus on advancement of the skills and these skills have to be relevant to the emerging economic environment. For transforming its demographic dividend, an efficient skill development system is the need of the hour. Therefore to achieve its ambitious skilling target, it is imperative to have holistic solutions of the challenges instead of piecemeal interventions.

Canada's performance in higher education and skills development has been fairly strong for many years. It leads the world in producing higher education graduates, the skills it acquire place Canada near the top of international rankings, and our highly skilled people contribute to economic prosperity, and social, political and individual well-being. But there are signs that Canada's skills and higher education performance is deteriorating, that not enough is being done to address a range of economic and social problems, and that opportunities and benefits have been poorly distributed across regions and groups. For these reasons, Canada needs to embark on an excellence and equity agenda for skills and higher education. 


\section{$\underline{\text { References: }}$}

- British Council. (2014). Understanding India: The future of higher education and opportunities for international cooperation. Retrieved in March 2017 from https://www.britishcouncil.in/sites/default/files/understanding_india.pdf

- FICCI \& EY. (2014). Higher education in India: Moving towards global relevance and competitiveness. FICCI Higher Education Summit 2014. Retrieved in March 2017 from http://www.ey.com/Publication/vwLUAssets/EY__Higher_education_in_India/\$FILE/EY-highereducation-in-india.pdf

- Munro, D. (2014). Skill and Higher Education in Canada: Towards Excellence and Equity. Retrieved in March 2017 from http://canada2020.ca/wpcontent/uploads/2014/05/2014_Canada2020_Paper-Series_Education_FINAL.pdf

- Sainai, V. (2015). Skill Development in India: Need, Challenges and ways forward. Abhinav National Monthly Refereed Journal of Research in Arts \& Education. 4, (4), 1-10. Retrieved in March 2017 from https://abhinavjournal.com/journal/index.php/ISSN-2277-1182/article/.../pdf_43

\section{Dr. Mayur Wadhwaniya}

